University of Nebraska - Lincoln

DigitalCommons@University of Nebraska - Lincoln

Faculty Publications, Department of Psychology

Psychology, Department of

February 2004

\title{
Nicotine as a signal for the presence or absence of sucrose reward: Pavlovian drug appetitive conditioning preparation in rats
}

\author{
Joyce Besheer \\ University of Nebraska-Lincoln \\ Matthew I. Palmatier \\ University of Nebraska-Lincoln \\ Dawn M. Metschke \\ University of Nebraska-Lincoln
}

Rick A. Bevins

University of Nebraska-Lincoln, rbevins1@unl.edu

Follow this and additional works at: https://digitalcommons.unl.edu/psychfacpub

Part of the Psychiatry and Psychology Commons

Besheer, Joyce; Palmatier, Matthew I.; Metschke, Dawn M.; and Bevins, Rick A., "Nicotine as a signal for the presence or absence of sucrose reward: Pavlovian drug appetitive conditioning preparation in rats" (2004). Faculty Publications, Department of Psychology. 77.

https://digitalcommons.unl.edu/psychfacpub/77

This Article is brought to you for free and open access by the Psychology, Department of at DigitalCommons@University of Nebraska - Lincoln. It has been accepted for inclusion in Faculty Publications, Department of Psychology by an authorized administrator of DigitalCommons@University of Nebraska - Lincoln. 
Published in Psychopharmacology 172:1 (2004), pp. 108-117. Copyright (C 2003 Springer-Verlag. Used by permission. DOI 10.1007/s00213-003-1621-9 http://www.springerlink.com/content/1432-2072/

\title{
Nicotine as a signal for the presence or absence of sucrose reward: Pavlovian drug appetitive conditioning preparation in rats
}

\author{
Joyce Besheer, Matthew I. Palmatier, Dawn M. Metschke, Rick A. Bevins* \\ Department of Psychology, University of Nebraska-Lincoln
}

Submitted June 2003; accepted August 2003; published online October 3, 2003.

\begin{abstract}
Rationale: In Pavlovian conditioning research, nicotine is typically conceptualized as the unconditioned stimulus (US) that becomes associated with an exteroceptive conditioned stimulus (CS). This research has not explored the possibility that nicotine can also function as a CS. Objectives: The present research examined whether nicotine served as a CS for the presence (CS+) or absence (CS-) of sucrose and started defining its specificity. Methods and results: Rats trained in the CS+ condition had nicotine $(0.4 \mathrm{mg} /$ $\mathrm{kg}$, base) paired intermittently with brief access to sucrose. Intermixed were saline sessions without sucrose. Nicotine acquired the ability to evoke goal tracking. This conditioned response (CR) decreased across extinction sessions. The CR was sensitive to nicotine dose $\left(\mathrm{ED}_{50}=0.113 \mathrm{mg} / \mathrm{kg}\right)$ and administration to testing interval; 0 -min and 100-min delays produced no $\mathrm{CR}$. The CS properties were specific to nicotine in that amphetamine and bupropion substitution was incomplete. Rats in the CS- condition received similar discrimination training except that sucrose was paired with saline. Nicotine also served as a CS-; the saline state CS+ acquired control of goal tracking. Mecamylamine, but not hexamethonium, blocked nicotine's ability to serve as a CS+ and CS-, indicating a role for central nicotinic acetylcholine receptors. Conclusions: Nicotine served as a signal for the presence or absence of sucrose. The extinction, CS-, and substitution results eliminated a psycho motor stimulant account. The conceptualization of nicotine as a CS suggests novel empirical research in which a drug acquires additional inhibitory and/ or excitatory value based on other outcomes present during its effects.
\end{abstract}

Keywords: Amphetamine, Bupropion, Dopamine, Drug discrimination, Nicotinic acetylcholine receptors, Smoking, Tobacco

*Corresponding author: e-mail: rbevins1@unl.edu

\section{Introduction}

Nicotine is the primary addictive compound within tobacco products. Of particular interest in the present report is the role that learned associative processes involving nicotine might have in tobacco dependence (Carmody 1990; Rose and Levin 1991; Henningfield et al. 1995, 1996; Lazev et al. 1999; Parrott 1999; Geier et al. 2000). Pavlovian (classical) conditioning, one source of these learned drug associations, typically consists of presenting a relatively neutral stimulus (conditioned stimulus; CS) in close temporal proximity to a more biologically relevant stimulus (unconditioned stimulus; US). Conditioning is evidenced when responding to the CS is modified relative to a control value (Pavlov 1927; Wasserman and Miller 1997). Translated for a typical smoker, the US is presumably the widespread stimulus conditions produced by nicotine (Eikelboom and Stewart 1982). The CS might include throat irritation, taste and odor of cigarettes, or cigarette pack, as well as situational cues such as drinking at a nightclub (Rose and Levin 1991; Rose et al. 1993; Pritchard et al. 1996; Geier et al. 2000).

Animal models have served to elucidate factors involved in acquisition and expression of Pavlovian conditioned associations with nicotine. Such models include conditioned taste avoidance, conditioned tolerance, place conditioning, and locomotor conditioning (Table 1). As summarized in Table 1, associative models and - by extension-tobacco addiction theories place nicotine in the role of the US. For example, in the research by Walter and Kuschinsky (1989), rats had a distinct environment (CS) repeatedly paired with nicotine (US). Controls received similar exposure to the CS and US in a temporally separated fashion. On the test day, both sets of rats were exposed to the CS without nicotine. 
Table 1 Animal models of Pavlovian conditioned associations with nicotine

\begin{tabular}{|c|c|c|c|c|}
\hline & $\begin{array}{l}\text { Conditioned } \\
\text { stimulus }\end{array}$ & $\begin{array}{l}\text { Unconditioned } \\
\text { stimulus }\end{array}$ & Conditioned response & References \\
\hline $\begin{array}{l}\text { Taste } \\
\text { conditioning }\end{array}$ & $\begin{array}{l}\text { Novel taste } \\
\text { (saccharin, sucrose) }\end{array}$ & $\begin{array}{l}\text { Nicotine } \\
\text { effects }\end{array}$ & $\begin{array}{l}\text { Decreased intake of taste, } \\
\text { increased aversive reaction } \\
\text { (chin rubs, gapes) }\end{array}$ & $\begin{array}{l}\text { Iwamoto and Williamson 1984; } \\
\text { Parker 1995; } \\
\text { Palmatier and Bevins } 2001\end{array}$ \\
\hline $\begin{array}{l}\text { Conditioned } \\
\text { tolerance }\end{array}$ & $\begin{array}{l}\text { Environment } \\
\text { (context) }\end{array}$ & $\begin{array}{l}\text { Nicotine } \\
\text { effects }\end{array}$ & $\begin{array}{l}\text { Decreased tail flick, paw lick, } \\
\text { heart rate, corticosterone, } \\
\text { and increased milk intake }\end{array}$ & $\begin{array}{l}\text { Epstein et al. } 1989 ; \\
\text { Caggiula et al. 1991; } \\
\text { Cepeda-Benito et al. } 1998\end{array}$ \\
\hline $\begin{array}{l}\text { Place } \\
\text { conditioning }\end{array}$ & $\begin{array}{l}\text { Environment } \\
\text { (context) }\end{array}$ & $\begin{array}{l}\text { Nicotine } \\
\text { effects }\end{array}$ & $\begin{array}{l}\text { Increased time in paired } \\
\text { environment; decreased time } \\
\text { in environment }\end{array}$ & $\begin{array}{l}\text { Fudala and Iwamoto } 1986 \text {; } \\
\text { Shoaib et al. } 1994\end{array}$ \\
\hline $\begin{array}{l}\text { Locomotor } \\
\text { conditioning }\end{array}$ & $\begin{array}{l}\text { Environment } \\
\text { (context) }\end{array}$ & $\begin{array}{l}\text { Nicotine } \\
\text { effects }\end{array}$ & $\begin{array}{l}\text { Increased activity, sniffing, } \\
\text { rearing, and extracellular } \\
\text { dopamine }\end{array}$ & $\begin{array}{l}\text { Walter and Kuschinsky } 1989 \text {; } \\
\text { Reid et al. 1996; } \\
\text { Bevins et al. } 2001\end{array}$ \\
\hline
\end{tabular}

Rats that had the context CS paired with nicotine displayed an increase in activity, sniffing, and rearing relative to controls. These differences were taken as evidence that the environment CS entered into a learned association with the psycho motor effects of nicotine (Bevins et al. 2001).

Conceptualizing nicotine as a potent US has allowed for important discoveries into basic mechanisms of nicotine dependence and contributed to advances in intervention strategies (e.g., extinction and counter-conditioning; see Rose and Levin 1991). In contrast, the possibility that the pharmacological effects of nicotine might serve as a CS that acquires new excitatory properties [i.e., evoke a conditioned response (CR)] has not been explored. This is not because nicotine lacks cueing properties. The substantial operant drug-discrimination literature leaves little doubt that the interoceptive effects of nicotine can guide reinforced responding. For example, the stimulus effects of nicotine can serve as a cue in rats for responding on one of two levers in an operant conditioning chamber. That is, if pretreated with nicotine $(0.4 \mathrm{mg} / \mathrm{kg}$, base) then responding ten consecutive times on the right lever (fixed ratio; FR10) is reinforced with food delivery. In this situation, nicotine is referred to as a discriminative stimulus or $\mathrm{S}^{\mathrm{D}}$. The opposite response-outcome relationship, left lever responding for food, is cued by administration of vehicle (Stolerman 1989).

Additionally, drug-drug conditioning research indicates that one drug can serve as a cue for response-independent delivery of another drug. For example, Revusky et al. (1989) gave rats repeated exposure to pentobarbital $(32 \mathrm{mg} / \mathrm{kg}) 30$ min before d-amphetamine $(24 \mathrm{mg} / \mathrm{kg})$. Pentobarbital was conceptualized as the CS and amphetamine as the US. Relative to drug-equated controls, the pentobarbital CS evoked an increase in heart rate. A variant of this drug-drug conditioning preparation assumes that the early pharmacological effects of a drug serve as a CS for the subsequent and typically more profound effects of the same drug (US). In an early demonstration with rats, Greeley et al. (1984) found that a low dose of ethanol $(0.8 \mathrm{~g} / \mathrm{kg})$ reliably paired with a later higher dose of ethanol $(2.5 \mathrm{~g} / \mathrm{kg})$ came to control an in- crease in body temperature (i.e., a compensatory hyperthermic CR). For a more recent example, see the research of Siegel and colleagues with morphine (Kim et al. 1999).

In contrast to the drug-drug conditioning situation, we were interested in associative processes involving a nondrug US (i.e., access to sucrose). To this end, we took advantage of a rat's tendency to search in a location where appetitive outcomes have reliably occurred in the past (i.e., goal tracking; Boakes 1977; Farwell and Ayres 1979). There were two main reasons for selecting goal tracking. First, it is an approach behavior directed to a discrete location (e.g., liquid dipper or pellet cup). This feature allows for a clear operational definition of the $\mathrm{CR}$ that is reliably observed in many laboratories despite differences in apparatus and protocols. Second, there is a substantial literature showing the utility of goal tracking for studying Pavlovian conditioning processes using more typical CSs (Davey and Cleland 1982; Delamater 1995; Lattal and Nakajima 1998; Rescorla 1999; Bouton and Sunsay 2003). With this in mind, the present research examined the ability of the pharmacological effects of nicotine to serve as a CS+ (signal for intermittent access to sucrose) and CS- (signal the absence of the US). As detailed below, we also investigated the specificity of the conditional stimulus effects of nicotine.

\section{Materials and methods}

\section{Animals}

Male Sprague Dawley rats from Harlan (Indianapolis, IN) were housed individually in plastic tubs lined with aspen shavings. Water was available in the home cage; access to food was restricted such that each rat was kept at $85 \%$ of its free feeding weight (374 $\pm 58 \mathrm{~g}$ ). About every 30 days this $85 \%$ weight was increased by 2 $\mathrm{g}$ to accommodate a typical growth curve. The colony was maintained on a 12-h/12-h light/dark cycle, and all sessions occurred in the light cycle. Experimental protocols were approved by the University of Nebraska-Lincoln IACUC and followed the "Guide for the Care and Use of Laboratory Animals" (National Research Council, 1996). 


\section{Apparatus}

Seven operant conditioning chambers (ENV-018, Med Associates, VT) measuring $30.5 \times 24.1 \times 21 \mathrm{~cm}(1 \times \mathrm{w} \times \mathrm{h})$ were used. Each chamber had aluminum sidewalls; the ceiling and front and back walls were clear poly carbonate. On the bottom center of one sidewall was a $5.2 \times 5.2-\mathrm{cm}(1 \times \mathrm{W})$ opening to a recessed dipper receptacle. The dipper arm had a $0.1-\mathrm{ml}$ cup that allowed delivery of a $32 \%$ sucrose solution $(\mathrm{w} / \mathrm{v})$. An emitter/detector unit, located $1.2 \mathrm{~cm}$ within the receptacle and $3 \mathrm{~cm}$ from the floor, was used to record head entries. Each chamber was housed in a sound-attenuating cubicle that had a fan providing airflow and masking noise. A personal computer with Med Associates interface and software-timed sessions recorded dipper entries and presented the sucrose.

\section{Drugs}

(-)-Nicotine hydrogen tartrate, mecamylamine hydrochloride, hexamethonium bromide, bupropion hydrochloride, and d-amphetamine sulfate (Sigma, St. Louis, MO) were dissolved in saline $(1 \mathrm{mg} / \mathrm{ml})$. Nicotine was brought to a $\mathrm{pH}$ of $7.0 \pm 0.1$ with a dilute $\mathrm{NaOH}$ solution. Nicotine, hexamethonium, and mecamylamine were injected subcutaneously (s.c.); Amphetamine and bupropion were injected intraperitoneally (i.p.). All injections were at a volume of $1 \mathrm{mg} / \mathrm{ml}$. Nicotine doses are expressed as the base form; all other drug doses are expressed as the salt form.

$\mathrm{Nic}+$ groups (nicotine as a $\mathrm{CS}+$ )

\section{Preliminary training}

On the first day, rats were trained to access the sucrose solution from anywhere in the chamber within $4 \mathrm{~s}$. The cubicle door was then closed and rats received a 25 -min automated session in which the probability of receiving 4-s access to sucrose in a 4-s interval was 0.1333 (two sucrose deliveries per minute). On the second day, rats received a 50-min automated session in which the probability of receiving 4-s access to sucrose in a 4-s interval started at 0.1333 and was decreased across the session to 0.05 (three sucrose deliveries per $4 \mathrm{~min}$ ). The chamber was dark during dipper training and for all subsequent sessions.

\section{Acquisition}

For 40 consecutive days, rats $(n=21)$ received nicotine $(\mathrm{Nic}+)$ and saline (Sal-) sessions intermixed. Before each Nic+ session, rats were injected s.c. with nicotine $(0.4 \mathrm{mg} / \mathrm{kg}) 5 \mathrm{~min}$ before placement in the chamber. A session lasted $20 \mathrm{~min}$ and $32 \mathrm{~s}$, during which there were eight sucrose presentations $(4 \mathrm{~s}$ each). To prevent rats from timing sucrose delivery, there were four nicotine session programs that varied when sucrose was presented. The average interval between sucrose deliveries was $141 \mathrm{~s}$ (range 90-210 $\mathrm{s})$; the average interval before the first sucrose delivery was $120 \mathrm{~s}$ (range 90-150 s). Rats were injected s.c. with saline $5 \mathrm{~min}$ before the start of a Sal- session. No sucrose was delivered in these sessions. However, four saline programs were generated that had 4$\mathrm{s}$ empty intervals that matched the nicotine programs for location of sucrose deliveries making session length identical for $\mathrm{Nic}+$ and Sal- sessions. Each rat was given the four nicotine and four saline programs in random order without replacement in eight-session cycles with the restriction that no more than two of one program type occurred consecutively. After acquisition training, rats were separated into three groups.

\section{Group 1: extinction, reacquisition, and generalization}

Rats $(n=7)$ began extinction training the day after the last acquisition session. During the 14 days of extinction, nicotine was administered as before, but sucrose was not presented. Reacquisition training began the day after extinction. This training was identical to initial acquisition and continued for 20 days: ten nicotine and ten saline sessions. Rats began generalization testing immediately following reacquisition. Generalization testing was conducted in 5-day cycles. Within a cycle, rats experienced two Nic+ and two Sal-sessions in random order. Thus, it took two testing cycles to use the eight programs from acquisition training. Day 5 of each cycle was a 4-min test in which a rat was injected s.c. with its assigned nicotine dose $(0.025,0.05,0.1,0.2,0.4$, or $0.6 \mathrm{mg} / \mathrm{kg}) 5$ min before the session - no sucrose was delivered. A rat was only tested if it met the criterion for that cycle (see Dependent measures). Rats that did not meet the criterion remained in the home cage. Each rat was tested twice on each nicotine dose. That is, once the rat completed its assigned testing order, testing on a new randomly selected order began.

\section{Group 2: injection to testing interval}

The day following the final acquisition session, rats $(n=7)$ began the 5-day testing cycle described for group 1 . On day 5 of each cycle was a temporal delay test in which rats were injected with the training dose of nicotine, $0,5,25$, or $50 \mathrm{~min}$ before placement in the chambers for the 4-min test. At the 0-min delay, a rat was injected with nicotine and immediately placed in the chamber. Rats were tested twice at each value.

\section{Group 3: nAChR antagonism}

Rats $(n=7)$ assigned to this group began the 5-day testing cycles the day after the final acquisition session. On the fifth day of the cycle, each rat was pretreated s.c. with saline, the central and peripheral nicotinic acetylcholine receptor (nAChR) antagonist mecamylamine [ $(0.5$ or $1.0 \mathrm{mg} / \mathrm{kg})$; see Martin et al. 1989], or the peripheral nAChR antagonist hexamethonium $[(2.5 \mathrm{mg} / \mathrm{kg}$ or 5.0 $\mathrm{mg} / \mathrm{kg}$ ); see Asghar and Roth 1971] $15 \mathrm{~min}$ before nicotine (i.e., $20 \mathrm{~min}$ before start of the test session). Rats were tested twice at each condition and nicotine $(0.4 \mathrm{mg} / \mathrm{kg})$ was administered $5 \mathrm{~min}$ before placement in the chambers (cf. training).

\section{Follow-up conditions}

As a rat in group 1-3 completed its assigned test values, training on the 5-day cycles continued. If the discrimination criterion was met, then an amphetamine substitution test was conducted on the fifth day to determine the specificity of the Pavlovian discrimination. For this substitution test, a rat was injected i.p. with saline or its assigned dose of amphetamine $(0.0625,0.125,0.25,0.5$, or $1.0 \mathrm{mg} / \mathrm{kg}$ ) and placed in the chamber $15 \mathrm{~min}$ later (Bevins et al. 1997). Rats $(n=18)$ were tested once on each dose. A subset of rats $(n=8)$ that completed the amphetamine substitution tests continued training and were tested on a dose of bupropion (10,20, or $40 \mathrm{mg}$ / $\mathrm{kg}$ ). This was of interest given its use as a pharmacotherapy (Zyban) and recent research showing its pharmacological effects substituted for a nicotine $S^{\mathrm{D}}$ (Young and Glennon 2002). Not all rats were tested on each dose (Table 2). Bupropion was injected i.p. 15 min before placement in the chambers (Munzar and Goldberg 2000). Following the bupropion test for some rats and the amphetamine test for other rats, an additional temporal delay test was conducted. This test was identical to the delay test described for group 2 except the values tested were $5 \mathrm{~min}$ and $100 \mathrm{~min}$. Rats $(n=11)$ were tested once at each delay. 
Table 2 Results from substitution tests

\begin{tabular}{lll}
\hline Dose $(\mathrm{mg} / \mathrm{kg})$ & $\begin{array}{l}\text { Mean dipper entries } \\
\text { per second }( \pm 1 \text { SEM })\end{array}$ & $n$ \\
\hline Amphetamine substitution & \\
Saline & $0.038( \pm 0.005)$ & 18 \\
0.0625 & $0.036( \pm 0.005)$ & 18 \\
0.125 & $0.044( \pm 0.005)$ & 18 \\
0.25 & $0.040( \pm 0.006)$ & 18 \\
0.5 & $0.055( \pm 0.007)^{*}$ & 18 \\
1.0 & $0.068( \pm 0.011)^{*}$ & 18 \\
\hline$* P 0.05$ as compared with saline & \\
\hline Dose $(\mathrm{mg} / \mathrm{kg})$ & Mean dipper entries \\
& per second $( \pm 1$ SEM) & \\
\hline Bupropion substitution & & 5 \\
Saline & $0.035( \pm 0.004)$ & 8 \\
10 & $0.055( \pm 0.012)$ & 8 \\
Saline & $0.035( \pm 0.010)$ & 5 \\
Saline & $0.074( \pm 0.017)^{*}$ & 5 \\
40 & $0.033( \pm 0.003)$ & \\
\hline
\end{tabular}

${ }^{*} P<0.05$ compared with respective saline value

Nic-group (nicotine as a CS-)

Preliminary and acquisition training

Following dipper training, rats $(n=7)$ began acquisition training similar to that of the Nic+ groups (e.g., nicotine dose, injection protocol, programs, etc.) except that sucrose was delivered during saline sessions ( $\mathrm{Sal}+$ ) and not during nicotine sessions (Nic-). Acquisition training continued for 64 days $[32$ sessions of each type (Sal+ and Nic-)].

\section{$n A C h R$ antagonism}

On the day following the final training session, rats began the 5-day testing cycles as previously described. On the fifth day of each cycle, rats that met criterion were injected s.c. with an assigned solution (saline, 0.5 or $1.0 \mathrm{mg} / \mathrm{kg}$ mecamylamine, or 2.5 or $5.0 \mathrm{mg} /$ $\mathrm{kg}$ hexamethonium) 15 min before administration of nicotine. Rats were tested twice with each solution.

\section{Dependent measure, criterion, and data analyses}

The main dependent measure was the number of dipper entries per second before sucrose was delivered. A per second measure was used because time between the beginning of the session and the first sucrose delivery varied across sessions. Dipper entries before the first sucrose delivery were used to avoid including dipper entries induced by sucrose. To equate for time, the programs used for sessions in which sucrose was not delivered (i.e., Sal- and Nic-) included comparable 4-s intervals. This procedural maneuver provides a per second measure of dipper entries for analysis using identical intervals. To meet criterion in the 5-day testing cycles, rats had to have more dipper entries per second during each sucrose session relative to both non-reinforced sessions of that cycle. Omnibus tests were one-or two-way repeated-measures analysis of variance (ANOVA). Post-hoc comparisons used paired $t$-tests. When a rat was tested twice on the same variable (e.g., drug dose or time delay), a single value for analysis was obtained by taking an average of the two values for each rat. For all tests, the dipper entries per second were from the first 2 min of the test. We used the first 2 min because it was comparable to the duration before first

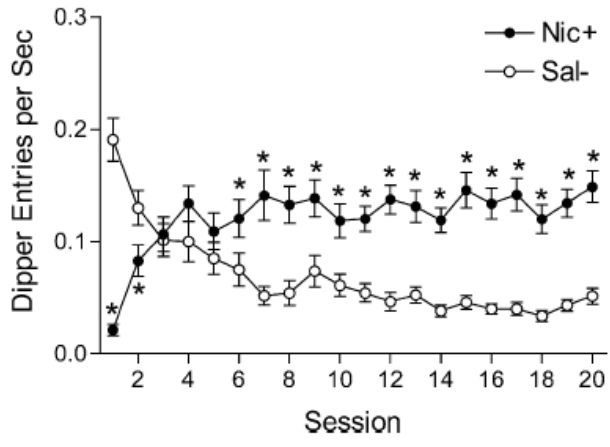

Fig. 1 Mean number of dipper entries per second ( \pm 1 SEM) before the first delivery of sucrose during nicotine (Nic+) and saline (Sal-) sessions for all rats $(n=21)$ in the acquisition phase. Asterisks (*) denote significant difference $(P<0.05)$ from the comparable Salsession

sucrose delivery during training and was the duration for the testing criterion. Statistical significance was declared using a two-tailed rejection region of 0.05 .

\section{Results}

$\mathrm{Nic}+$ groups

Acquisition. Figure 1 shows the results of the acquisition phase for rats that were trained with nicotine as a CS+. Given that training was identical for all groups, the data were pooled. The two-way, repeated-measures ANOVA revealed a main effect of session $\left(F_{19.380}=1.781, P=0.023\right)$, of condition (Nic+ vs Sal-; $F_{1,20}=48.273, P<0.001$ ), and a significant session $\times$ condition interaction $\left(F_{19,380}=18.438, P<0.001\right)$. On the first and second sessions, nicotine suppressed dipper entries $(P$ values $\leq 0.007)$. As training continued, nicotine acquired control over goal tracking. From the sixth session on, there were more dipper entries on $\mathrm{Nic}+$ sessions than $\mathrm{Sal}-$ sessions (values $\leq 0.024$ ).

\section{Group 1}

Extinction. Figure 2A shows the results from the extinction phase. For comparison, the solid line illustrates the average dipper entries per second for the two saline sessions immediately before extinction; dashed lines represent the SEM. There was a significant main effect of $\operatorname{session}\left(F_{13,78}=6.994\right.$, $P<0.0001$ ), indicating that dipper entries decreased across sessions. To examine whether dipper entries returned to levels maintained in the absence of sucrose (complete extinction), goal tracking in each extinction session was compared with saline. Goal tracking was significantly greater than that maintained in the Sal- condition on extinction sessions 1-4, and $9(P$ values $<0.05)$ 

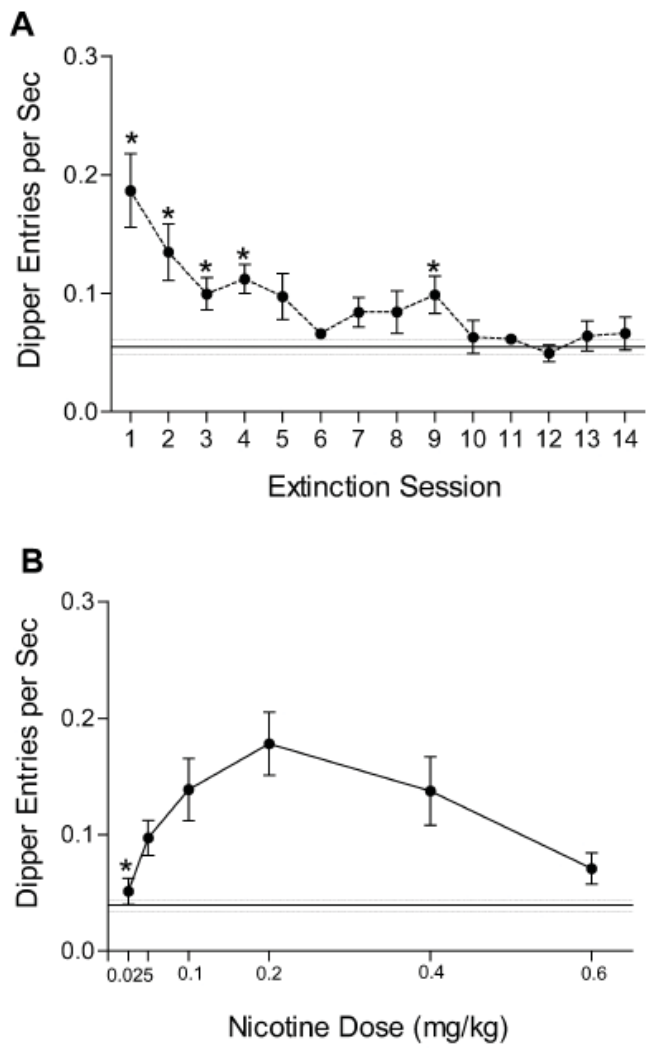

Fig.2 A Mean dipper entries per second ( \pm 1 SEM) for the first 2 min of each extinction session for rats in group 1 $(n=7)$. The solid line represents the average of the first 2 min for the three saline sessions before extinction. Dashed lines represent the SEM. Asterisks denote significant difference from the saline session average $(P<0.05)$. B Average dipper entries per second for the first 2 min of the nicotine generalization tests for the same rats after reacquisition training. The solid line reflects the average of the first $2 \mathrm{~min}$ of the two saline sessions that preceded testing on the $0.4 \mathrm{mg} / \mathrm{kg}$ dose. Dashed lines represent the SEM. The asterisk denotes significant difference from the training dose of nicotine $(0.4$ $\mathrm{mg} / \mathrm{kg} ; P<0.05)$.

Nicotine generalization test. As a no-drug baseline, we calculated the average dipper entries per second for the first 2 min of the two saline sessions that preceded testing on the training dose (solid line in Fig. 2B). Because rats were tested twice on each dose, we used the saline sessions before the first test of the training dose $(0.4 \mathrm{mg} / \mathrm{kg})$ for four rats; the value from the second test was used for the remaining three rats. The oneway ANOVA revealed a significant effect of nicotine dose $\left(F_{5,30}=8.654, P<0.0001\right)$. Post-hoc comparisons tested whether each dose was different from the training dose. Goal tracking was significantly lower at the $0.025-\mathrm{mg} / \mathrm{kg}$ dose of nicotine $(P<0.05)$. There was a tendency for a difference at the $0.6-\mathrm{mg} / \mathrm{kg}$ dose $(P=0.052)$. Using the linear portion of the dose-effect curve $(0.025-0.2 \mathrm{mg} / \mathrm{kg})$, the median effective dose $\left(\mathrm{ED}_{50}\right)$ for the nicotine $\mathrm{CS}+$ was $0.113 \mathrm{mg} / \mathrm{kg}$.

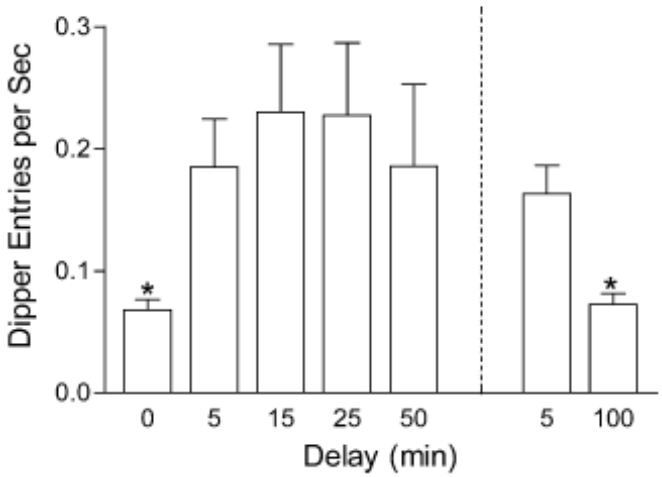

Fig.3 Mean number of dipper entries per second ( \pm 1 SEM) for the first 2 min of the temporal delay tests for rats in group $2(n=7)$. The two right-most bars are from a separate follow-up test of the administration to testing interval $(n=11)$. Asterisks denote significant difference from the training delay $(5 \mathrm{~min} ; P<0.05)$.

\section{Group 2}

Injection to testing interval. Changing the time of the nicotine injection before placement in the chamber significantly affected goal-tracking behavior $\left(F_{4,24}=5.094, P=0.004\right.$; left portion of Fig. 3). Specifically, nicotine administered immediately before placement in the chamber significantly decreased dipper entries when compared with the 5-min training delay. Continued goal-tracking at the 50-min delay prompted the follow-up condition in which a 5-min and 100min delay were assessed (right-most bars of Fig. 3). Relative to the 5-min delay, extending the delay to $100 \mathrm{~min}$ significantly reduced dipper entries $\left(t_{10}=5.026, P=0.0005\right)$.

\section{Group 3}

$n A C h R$ antagonism. Figure 4 shows the results from the antagonism tests. For these tests, a separate repeated-measures ANOVA was conducted for each antagonist; saline values were used for both ANOVAs. Hexamethonium pretreatment had no effect on dipper entries $\left(F_{2,12}=1.487\right)$. In contrast, mecamylamine significantly reduced dipper entries $\left(F_{2,12}=30.42, P<0.0001\right)$. Relative to saline, this reduction in goal tracking was evident at both mecamylamine doses ( $P$ values $<0.002$ ), and suggests that the conditional stimulus properties of nicotine are mediated by centrally located nAChRs.

\section{Follow-up conditions}

Amphetamine substitution. The results from the amphetamine substitution tests are shown in the top portion of Table 2. The overall ANOVA was significant $\left(F_{5,85}=4.905, P=0.0005\right)$. Subsequent post-hoc tests compared each amphetamine dose with saline. The two highest amphetamine doses $(0.5 \mathrm{mg} / \mathrm{kg}$ and $1.0 \mathrm{mg} / \mathrm{kg})$ increased the number of dipper entries relative to saline 


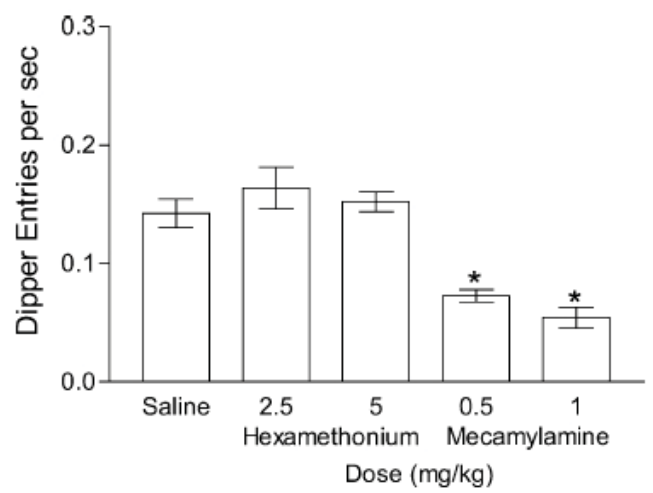

Fig.4 The left-most set of bars reflect the mean number of dipper entries per second ( \pm 1 SEM) for the first 2 min of the antagonism tests for rats in group $3(n=7)$. Hexamethonium and mecamylamine were administered 20 min before the start of the test (i.e., $15 \mathrm{~min}$ before nicotine). Asterisks denote significant difference from saline $(P<0.05)$

( $P$ values $<0.02)$. To determine whether this increase was complete substitution for the nicotine CS, goal tracking evoked by these two doses of amphetamine was compared with goal tracking in the comparable time period of the nicotine training session that immediately preceded testing of the $1.0-\mathrm{mg} / \mathrm{kg}$ amphetamine dose. Nicotine controlled significantly more goal tracking $(0.163 \pm 0.023$ dipper entries per second) than either amphetamine doses $(0.5$ and $1.0 \mathrm{mg} /$ $\mathrm{kg}$; $P$ values $<0.0001$ ).

Bupropion substitution. Given the identical injection protocols, each bupropion dose was compared with the saline data collected during the amphetamine substitution phase. Not all rats were tested on each bupropion dose, thus each paired $t$ test used saline data only from rats that were tested with the bupropion dose being analyzed (lower portion of Table 2). Only the $20-\mathrm{mg} / \mathrm{kg}$ dose bupropion increased dipper entries relative to saline $\left(t_{7}=2.847, P=0.025\right)$. The extent of goal tracking to the $20-\mathrm{mg} / \mathrm{kg}$ bupropion dose was significantly less than that seen in the first 2 min of the nicotine session that preceded testing $(0.094 \pm 0.017$ dipper entries per second; $P=0.023$ ).

Nic- group

Acquisition. Figure 5A shows the results of the acquisition phase for rats that were trained with nicotine as a CS- . The ANOVA revealed a main effect of condition $\left(F_{1,6}=18.398\right.$, $P=0.005)$, of session $\left(F_{31,186}=1.644, P=0.024\right)$, and a significant session $\times$ condition interaction $\left(F_{31,186}=1.822, P=0.008\right)$. The variability in this group measure highlights two important results. First, it suggests that only a subset of rats acquired the discrimination by the end of this phase (Fig. 5B). Indeed, four of the seven rats had all positive difference scores (saline per second value minus nicotine value) in the last cycle of this phase indicating consistently more dipper entries in $\mathrm{Sal}+$
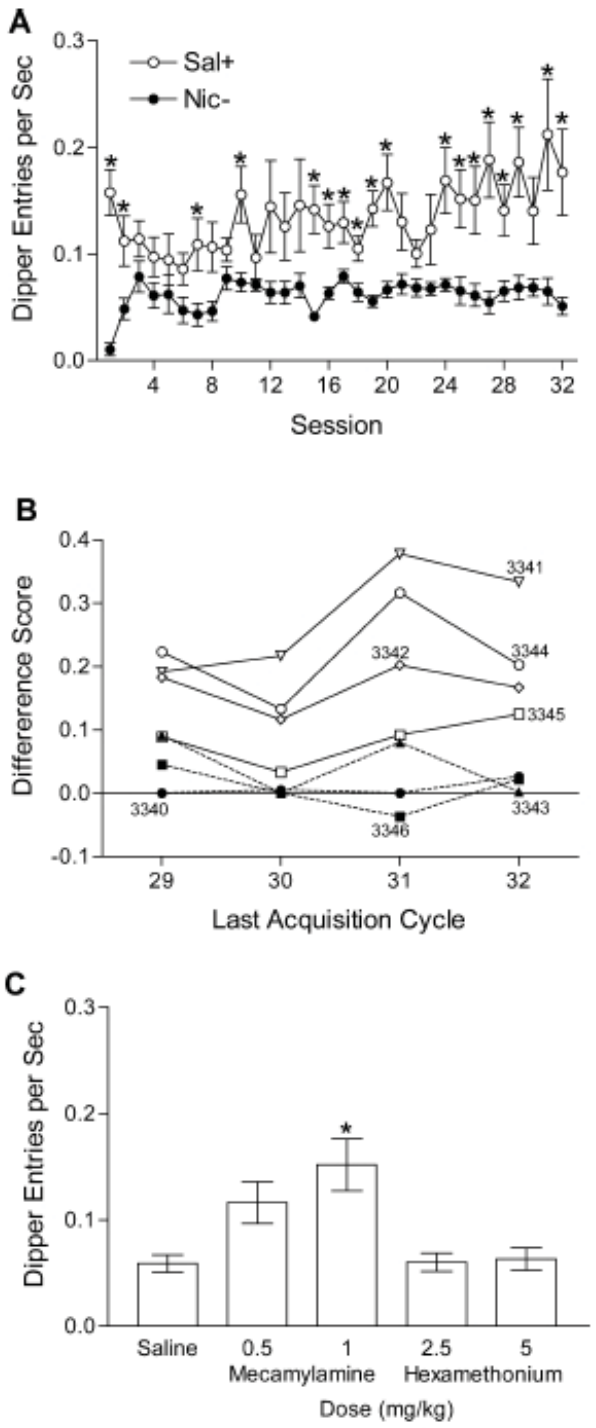

Fig.5 A Mean number of dipper entries per second ( \pm 1 SEM) before the first delivery of sucrose during saline $(\mathrm{Sal}+)$ and nicotine (Nic-) sessions for rats in the nicotine CS- condition. Asterisks denote significant difference $(P<0.05)$ from the comparable nicotine session. B Difference score for each rat during sessions 29 through 32. The open symbols represent rats with consistently positive difference scores. The filled symbols with dashed lines represent rats that did not acquire the discrimination by the last cycle of the acquisition phase. $\mathbf{C}$ Mean dipper entries per second for the first 2 min of the antagonism tests. Hexamethonium and mecamylamine were administered $20 \mathrm{~min}$ before the start of the test (i.e., $15 \mathrm{~min}$ before nicotine). Asterisk denotes significant difference from saline $(P<0.05)$.

sessions. Second, the source of the variability was not in withholding responding during nicotine CS- sessions. Rather, the variability was in the use of the non-drug state (operant chamber cues) as the cue for access to the US. 


\section{$n A C h R$ antagonism}

A separate ANOVA was conducted for each antagonist using the same saline values. Pretreatment with mecamylamine increased dipper entries $\left(F_{2,12}=8.106, P=0.006\right.$; Fig. 5C). Relative to saline, this recovery of goal tracking with mecamylamine (cf. Sal+) was significant only at the $1.0-\mathrm{mg} / \mathrm{kg}$ dose $(P<0.018)$. In contrast, hexamethonium pretreatment had no effect on dipper entries $(F<1)$, indicating that central $\mathrm{nAChRs}$ likely mediate the ability of nicotine to serve as a CS-.

\section{Discussion}

In the early nicotine $\mathrm{CS}+$ acquisition sessions, nicotine suppressed dipper entries below the level seen in early saline sessions. This suppression likely reflects motor ataxia typically seen with higher nicotine doses (Stolerman et al. 1973; Bevins et al. 2001). This suppression dissipated across sessions, and nicotine came to control more dipper entries before first sucrose delivery than saline. We interpret this pattern as reflecting tolerance to the locomotor suppressant effects of nicotine (Stolerman et al. 1973; Clarke and Kumar 1983) and acquisition of an appetitive conditioned association between nicotine and sucrose such that the nicotine CS evokes goal tracking (Farwell and Ayres 1979).

Chronic exposure to nicotine induces locomotor stimulation in rats (Clarke and Kumar 1983; Bevins et al. 2001). An alternative to this conditioning account suggests that the activating effects of nicotine increase the rate of dipper entries. The results from the extinction manipulation do not support this stimulant account. That account predicts no change in the level of dipper entries when the sucrose US is withheld in the extinction phase because nicotine was still present to activate dipper entries. This did not occur. Rather, nicotine-evoked goal tracking decreased systematically across repeated extinction sessions. This sensitivity to removal of the US is an important feature of Pavlovian conditioned associations (Pavlov 1927; Wasserman and Miller 1997) and suggests that the pharmacological effects of nicotine entered into an excitatory association with sucrose.

A variant of the stimulant account suggests that availability of sucrose during acquisition alters the probability of particular behaviors. For example, the chamber for each rat was paired with sucrose $50 \%$ of the time. Perhaps intermittent pairings make the exteroceptive cues that compose the chamber mildly excitatory. This weak conditioned excitation might be enhanced by a psycho motor stimulant with appetitive properties such as nicotine. The extinction phase changed the probability of chamber-sucrose pairings to 0 . This non-reinforcement would have a cumulative effect on the frequency of different behaviors including dipper entries. This modified stimulant account predicts that administration of another psycho motor stimulant with appetitive effects should similarly increase dipper entries as long as the chamber cues were not extinguished. This did not occur. Amphetamine $(0.5 \mathrm{mg} / \mathrm{kg}$ and $1 \mathrm{mg} / \mathrm{kg})$ did not even increase dipper entries to half that controlled by nicotine even though these doses of amphetamine readily stimulate a wide range of behaviors (Garrett and Holtzman 1996; Antoniou et al. 1998; Badiani et al. 2000). Indeed, in our laboratory, these doses of amphetamine are more potent at activating locomotor behavior than nicotine (Palmatier et al. 2003).

In two ways, a conditioning interpretation is further supported by the finding that nicotine can serve as a signal for the absence of sucrose (CS-). First, there is a substantial Pavlovian conditioning literature showing that exteroceptive stimuli can readily signal the absence of an US (Pavlov 1927; Bouton and Brooks 1993; Tinsley et al. 2002). The present results suggest that nicotine also has this ability to function as a CS-. An interesting possibility is that the nicotine CS- has become a conditioned inhibitor. Procedurally it is plausible because the nicotine cue occurs in the presence of an excitatory cue (i.e., the chamber). However, establishing whether the nicotine $\mathrm{CS}$ - has acquired inhibitory properties will require additional research using specifically developed procedures (Pavlov 1927; Rescorla 1969; Wasserman at al. 1974). Second, nicotine's ability to function as a CS- is inconsistent with either variant of the stimulant account of the $\mathrm{CS}+$ data. That is, appetitive food-seeking behaviors were readily withheld during the nicotine $\mathrm{CS}_{-}$, a result more consistent with a conditioning interpretation.

Conditional control of goal tracking was dose dependent. From a conditioning perspective, this result is important because it demonstrates that changes in the salience of the training CS result in alterations in the CR. Similar results have been reported in a wide range of Pavlovian conditioning preparations (Rohrbaugh et al. 1971; Scavio and Gormezano 1974; Brennan 1975; Czaplicki et al. 1976). The ability to generate an orderly dose-effect function suggests that this preparation might be utilized to study the neuropharmacological processes mediatingthe ability of a drug to serve as a CS in much the same fashion that drug discrimination is used to study processes mediating a drug's ability to serve as a $S^{\mathrm{D}}$. The generalization function described for the nicotine $\mathrm{CS}+$ is similar to that reported in the drug-discrimination literature (Chance et al. 1977; Pratt et al. 1983; Stolerman et al. 1984; Shoaib et al. 1997). Also, the $\mathrm{ED}_{50}$ for the conditional stimulus effects of nicotine using goal tracking $(0.113 \mathrm{mg} / \mathrm{kg})$ was in the same range as previous drug-discrimination research using lever pressing [e.g., Chance et al. $1977\left(\mathrm{ED}_{50}=0.087 \mathrm{mg} /\right.$ $\mathrm{kg})$; Pratt et al. $\left.1983\left(\mathrm{ED}_{50}=0.14 \mathrm{mg} / \mathrm{kg}\right)\right]$.

Nicotine's ability to serve as a CS+ or CS- appears to be mediated by centrally located nAChRs. For the CS+, goal tracking was blocked by pretreatment with mecamylamine $(0.5 \mathrm{mg} / \mathrm{kg}$ and $1 \mathrm{mg} / \mathrm{kg})$ but not by hexamethonium. Similar results have been reported for the discriminative stimulus effects of nicotine (Morrison and Stephenson 1969; Stolerman et al. 1984). For the nicotine CS-, goal tracking increased to saline levels (i.e., the 
$\mathrm{CS}+$ ) with pretreatment of mecamylamine $(1 \mathrm{mg} / \mathrm{kg})$, but not hexamethonium. This latter result is notable because antagonism is evidenced as an increase in dipper entries. This feature eliminates any motor impairment account of mecamylamine blockade of goal tracking to the nicotine CS+.

The nature of the nicotine CS+ varied with time since administration. Goal tracking was significantly reduced when nicotine was injected immediately or $100 \mathrm{~min}$ before testing. Given that CS-elicited goal tracking is mediated by central nAChRs, this time-dependent data pattern is likely due to changes in brain concentrations of nicotine. For example, Ghosheh et al. (1999) measured brain concentrations of nicotine in rats at different time points after a s.c. injection of $0.8 \mathrm{mg} / \mathrm{kg}$ nicotine (base). Ghosheh et al.'s (1999) temporal-effect curve for brain levels of nicotine nicely parallels our temporal-effect function for goal tracking with concentrations of nicotine peaking at $5 \mathrm{~min}$ after the injection and, thereafter, declined resulting in a half-life of $52 \mathrm{~min}$. Thus, the loss of goal tracking at the 100-min interval likely reflects a significant decrease in brain levels of nicotine. A reduction in goal tracking when the nicotine CS+ was administered immediately before the test suggests that the brain concentration of nicotine had not reached sufficient levels (Pratt et al. 1983). Similar temporal-effect functions have been reported in the operant drug-discrimination literature (Hirschhorn and Rosecrans 1974; Chance et al. 1977; Pratt et al. 1983; Schechter and Meehan 1992).

The ability of nicotine to serve as a CS+ was not based on a drug versus no-drug discrimination. If this had occurred, amphetamine and bupropion would have fully substituted for the nicotine CS. Instead, amphetamine and bupropion only partially substituted for nicotine indicating stimulus-specific control of goal tracking by nicotine. Incomplete substitution by amphetamine further suggests that the appetitive discrimination was not based on dopaminergic processes or stimulant properties shared by nicotine and amphetamine. This outcome and conclusion is consistent with the operant drugdiscrimination literature. That research, using different training and testing procedures consistently reports an inability of amphetamine to completely substitute for a nicotine $\mathrm{S}^{\mathrm{D}}$ (Morrison and Stephenson 1969; Schechter and Rosecrans 1972; Stolerman et al. 1984; Mansbach et al. 1998).

Bupropion substitution for the nicotine CS+ was also incomplete suggesting that any similar effect by nicotine and bupriopion on dopamine-containing neurons (Ferris et al. 1983; Ascher et al. 1995; Seppä and Ahtee 2000; Yin and French 2000), at least alone, is not responsible for nicotine's ability to serve as a CS+. The operant drug-discrimination literature is mixed on bupropion substitution for nicotine (full substitution: Wiley et al. 2002; Young and Glennon 2002; no substitution: Shoaib et al. 2003). Further research will be required to determine the procedural details that affect bupropion's ability to evoke nicotine-like responding in both preparations.

One might suggest that differential control of goal tracking reflects state-dependent learning (Overton 1964;
Cunningham 1979). With the nicotine CS+ procedure, this would mean that goal tracking is controlled by the chamber cues. However, this chamber-sucrose association is more readily recalled under the effects of nicotine. For the CScondition, nicotine decreases recall of the chamber-sucrose association learned in a saline state. To our knowledge, the only repeatable demonstration of state-dependent learning with nicotine uses human smokers and recall of word lists (Peters and McGee 1982; Warburton et al. 1986). Like other tasks using abstaining smokers, it is unclear whether effects are attributable to nicotine withdrawal or state dependency. This, and the fact that there have been numerous demonstrations that nicotine typically enhances performance on a learned task even when nicotine is not administered during testing (Levin and Simon 1998), decreases our enthusiasm for a state-dependency account.

In the present research, sucrose was delivered independent of the rat's behavior. From a procedural perspective, this is a Pavlovian procedure in which a stimulus (nicotine) is reliably paired with another stimulus (sucrose). According to this perspective, nicotine has acquired appetitive-motivational value. Because rats have evolutionarily pre-disposed approach tendencies to stimuli that have appetitive qualities (Bolles 1970; Ikemoto and Panksepp 1999), stimuli associated with these appetitive effects also come to control approach behaviors (i.e., goal tracking). Notably, the rat must insert its head into the recessed dipper to access the sucrose. Thus, embedded within the experimental protocol is a response-outcome relationship. If one views the adventitious reinforcement of dipper entries as the controlling variable, then nicotine may be conceptualized as an $\mathrm{S}^{\mathrm{D}}$. The present research was not designed to assess the relative contribution of stimulus-outcome and response-outcome contingencies. However, research that has tried with discrete exteroceptive stimuli has been mixed suggesting that both contingencies might be important (Boakes 1977; Farwell and Ayres 1979). For now, we prefer to use the descriptive and theoretical language provided by the Pavlovian conditioning perspective if for no other reason than it suggests novel empirical research in which drugs serve as CSs acquiring inhibitory and/or excitatory value.

\section{Acknowledgements}

We thank John Roll for his thoughtful comments on an earlier version of this report. The research and R. Bevins were partially supported by United States Public Health Service grant DA11893. J. Besheer, now in the Bowles Center for Alcohol Studies at the University of North Carolina-Chapel Hill, was supported by USPHS grant DA06092 while conducting this research. R. Bevins prepared portions of this manuscript while on faculty development leave in the Behavioral Neuroscience Department at Oregon Health Sciences University. We thank them for their generous support and specifically Chris Cunningham for providing an energizing environment in which to discuss this research. 


\section{References}

Antoniou K, Kafetzopoulos E, Papadopoulou-Daifoti Z, Hyphantis T, MarselosM(1998) d-Amphetamine, cocaine and caffeine: a comparative study of acute effects on locmotor activity and behavioral patterns in rats. Neurosci Biobehav Rev 23:189-196

Ascher J, Cole J, Colin J, Feigher J, Ferris R, Fibiger J, Golden R, Martin P, Potter W, Richelson E, Sulser F (1995) Bupropion:a review of its mechanism of antidepressant activity. J Clin Psychiatry 56:395-401

Asghar K, Roth LJ (1971) Entry and distribution of hexamethonium in the central nervous system. Biochem Pharmacol 20:2787-2795

Badiani A, Oates MM, Fraioli S, Browman KE, Ostrander MM, Xue CJ, Wolf ME, Robinson TE (2000) Environmental modulation of the response to amphetamine: dissociation between changes in behavior and changes in dopamine and glutamate overflow in the rat striatal complex. Psychopharmacology 151:166-174

Bevins RA, Klebaur JE, Bardo MT (1997) Individual differences in response to novelty, amphetamine-induced activity and drug discrimination in rats. Behav Pharmacol 8:113-123

Bevins RA, Besheer J, Pickett KS (2001) Nicotine-conditioned locomotor activity in rats: dopaminergic and GABAergic influences on conditioned expression. Pharmacol Biochem Behav 68:135-145

Boakes RA (1977) Performance on learning to associate a stimulus with positive reinforcement. In: Davis H, Hurwitz HMB (eds) OperantPavlovian interactions. Lawrence Erlbaum Associates, Hillsdale, NJ, pp 67-101

Bolles RC (1970) Species-specific defense reactions and avoidance learning. Psychol Rev 77:32-48

Bouton ME, Brooks DC (1993) Time and context effects on performance in a Pavlovian discrimination reversal. J Exp Psychol Anim Behav Process 19:165-179

Bouton ME, Sunsay C (2003) Importance of trial versus accumulating time across trials in partially reinforced appetitive conditioning. J Exp Psychol Anim Behav Process 29:62-77

Brennan JF (1975) Differential response gradients to a Pavlovian safety signal following active avoidance training in young and adult rats. Anim Learn Behav 3:277-281

Caggiula AR, Epstein LH, Antelman SM, Saylor SS, Perkins KA, KnopfS, StillerR(1991) Conditioned tolerancetothe anorectic and corticosterone-elevating effects of nicotine. Pharmacol Biochem Behav 40:53-59

Carmody TP (1990) Preventing relapse in the treatment of nicotine addiction: current issues and future directions. J Psychoactive Drugs 22:211-238

Cepeda-Benito A, Reynoso J, McDaniel EH (1998) Associative tolerance to nicotine analgesia in the rat: tail-flick and hot-plate tests. Exp Clin Psychopharmacol 6:248-254

Chance WT, Murfin D, Krynock GM, Rosecrans JA (1977) A description of the nicotine stimulus and tests of its generalization to amphetamine. Psychopharmacology 55:19-26

Clarke PBS, KumarR (1983) The effects of nicotine on locomotor activity in tolerant and non-tolerant rats. Br J Pharmacol 78:329-337

Cunningham CL (1979) Alcohol as a cue for extinction: state dependency produced by conditioned inhibition. Anim Learn Behav 7:45-52

Czaplicki JA, Borrebach DE, Wilcoxon HC (1976) Stimulus generalization of an illness-induced aversion to different intensities of colored water in Japanese quail. Anim Learn Behav 4:45-48

Davey GC, Cleland GG (1982) The effect of partial reinforcement on the acquisition and extinction of sign-tracking and goal-tracking in the rat. Bull Psychonom Soc 19:115-118

Delamater AR (1995) Outcome-selective effects of intertrial reinforcement in a Pavlovian appetitive conditioning paradigm with rats. Anim Learn Behav 23:31-39

Eikelboom R, Stewart J (1982) Conditioning of drug-induced physiological responses. Psychol Rev 89:507-528
Epstein LH, Caggiula AR, Stiller R (1989) Environment-specific tolerance to nicotine. Psychopharmacology 97:235-237

Farwell BJ, Ayres JJB (1979) Stimulus-reinforcer and response-reinforcer relations in the control of conditioned appetitive head poking ("goal tracking") in rats. Learn Motiv 10:295-312

Ferris R, Cooper B, Maxwell R (1983) Studies of bupropion's mechanism of antidepressant activity. JClin Psychiatry 44:74- 78

Fudala PJ, Iwamoto ET (1986) Further studies on nicotine-induced conditioned place preference in the rat. Pharmacol Biochem Behav 25:1041-1049

Garrett BE, Holtzman SG (1996) Comparison of the effects of prototypical behavioral stimulants on locomotor activity and rotational behavior in rats. Pharmacol Biochem Behav 54:469- 477

GeierA, MuchaRF, PauliP (2000) Appetitive nature of drug cues confirmed with physiological measures in a model using pictures of smoking. Psychopharmacology 150:283-291

Ghosheh O, Dwoskin LP, Li W-K, Crooks PA (1999) Residence times and half-lives of nicotine metabolites in rat brain after acute peripheral administration of $\left[20-{ }^{14} \mathrm{C}\right]$ nicotine. Drug Metab Dispos 27:14481455

Greeley J, Lê DA, Poulos CX, Cappell H (1984) Alcohol is an effective cue in the conditioned control of tolerance to alcohol. Psychopharmacology 83:159-162

Henningfield JE, Schuh LM, Jarvik ME (1995) Pathophysiology of tobacco dependence. In: Bloom FE, Kupfer DJ (eds) Psychopharmacology: the fourth generation of progress. Raven Press, New York, pp 1715-1729

Henningfield JE, Keenan RM, Clarke PBS (1996) Nicotine. In: Schuster CR, Kuhar MJ (eds) Pharmacological aspects of drug dependence: toward an integrated neurobehavioral approach. Springer, Berlin Heidelberg New York, pp 271-314

Hirschhorn ID, Rosecrans JA (1974) Studies on the time course and the effect of cholinergic and adrenergic receptor blockers on the stimulus effects of nicotine. Psychopharmacolgia 40:109-120

Ikemoto S, Panksepp J (1999) The role of nucleus accumbens dopamine in motivated behavior: unifying interpretation with special reference to reward-seeking. Brain Res Rev 31:6-41

Iwamoto ET, Williamson EC (1984) Nicotine-induced taste aversion: characterization and preexposure effects in rats. Pharmacol Biochem Behav 21:527-532

Kim JA, Siegel S, Patenall VRA (1999) Drug-onset cues as signals: intraadministration associations and tolerance. J Exp Psychol Anim Behav Process 25:491-504

Lattal KM, Nakajima S (1998) Over expectation in appetitive Pavlovian and instrumental conditioning. Anim Learn Behav 26:351-360

Lazev AB, Herzog TA, Brandon TH (1999) Classical conditioning of environmental cues to cigarette smoking. Exp Clin Psychopharmacol $7: 56-63$

Levin ED, Simon BB (1998) Nicotinic acetylcholine involvement in cognitive function in animals. Psychopharmacology 138:217-230

Mansbach RS, Rovetti CC, Freeland CS (1998) The role of monoamine neurotransmitter systems in the nicotine discriminative stimulus. Drug Alcohol Depend 52:125-134

Martin BR, Onaivi ES, Martin TJ (1989) What is the nature of mecamylamine's antagonism of the central effects of nicotine? Biochem Pharmacol 38:3391-3397

Morrison CF, Stephenson JA (1969) Nicotine injections as the conditioned stimulus in discrimination learning. Psychopharmacologia 15:351360

Munzar P, Goldberg SR (2000) Dopaminergic involvement in the discriminative-stimulus effects of methamphetamine in rats. Psychopharmacology 148:209-216

Overton DA (1964) State-dependent or "dissociated" learning produced with pentobarbital. J Comp Physiol Psychol 57:3-12

Palmatier MI, Bevins RA (2001) Chronic caffeine exposure in rats blocks a subsequent nicotine-conditioned taste avoidance in a 1-bottle, but not a 2-bottle test. Pharmacol Biochem Behav 70:279-289 
Palmatier MI, Fung EYK, Bevins RA (2003) Effects of chronic caffeine preexposure on the conditioned and unconditioned psycho motor activity induced by nicotine and amphetamine in rats. Behav Pharmacol 14:191-198

Parker LA (1995) Rewarding drugs produce taste avoidance, but not taste aversion. Neurosci Biobehav Rev 19:143-157

Parrott AC (1999) Does cigarette smoking cause stress? Am Psychol $54: 817-820$

Pavlov IP (1927) Conditioned reflexes. Oxford University Press, London

Peters R, McGee R (1982) Cigarette smoking and state-dependent memory. Psychopharmacology 76:232-235

Pratt JA, Stolerman IP, Garcha HS, Giardini V, Feyerabend C (1983) Discriminative stimulus properties of nicotine: further evidence for mediation at a cholinergic receptor. Psychopharmacology 81:54-60

Pritchard WS, Robinson JH, Guy TD, Davis RA, Stiles MF (1996) Assessing the sensory role of nicotine in cigarette smoking. Psychopharmacology 127:55-62

Reid MS, Ho LB, Berger SP (1996) Effects of environmental conditioning on the development of nicotine sensitization: Behavioral and neurochemical analysis. Psychopharmacology 126:301-310

Rescorla RA (1969) Pavlovian conditioned inhibition. Psychol Bull 72:7794

Rescorla RA (1999) Learning about qualitatively different outcomes during a blocking procedure. Anim Learn Behav 27:140-151

Revusky S, Davey V, Zagorski M (1989) Heart-rate conditioning with pentobarbital as a conditioned stimulus and amphetamine as an unconditioned stimulus. Behav Neurosci 103:296-307

Rohrbaugh M, Brennan JF, Riccio DC (1971) Control of two-way shuttle avoid ancein rats by auditory frequency and intensity. J Comp Physiol Psychol 75:324-330

Rose JE, Levin ED (1991) Inter-relationships between conditioned and primary reinforcement in the maintenance of cigarette smoking. BrJ Addict 86:605-609

Rose JE, Behm FM, Levin ED (1993) Role of nicotine dose and sensory cues in the regulation of smoke intake. Pharmacol Biochem Behav 44:891-900

Scavio MJ, Gormezano I (1974) CS intensity effects on rabbit nictitating membrane conditioning, extinction and generalization. PavlovianJ Biol Sci 9:25-34

Schechter MD, Meehan SM (1992) Further evidence for the mechanisms that may mediate nicotine discrimination. Pharmacol Biochem Behav 41:807-812

Schechter MD, Rosecrans JA (1972) Nicotine as a discriminative cue in rats: inability of related drugs to produce a nicotine-like cueing effects. Psychopharmacologia 27:379-387
Sepp_ T, AhteeL (2000) Comparison of the effects of epibatidine and nicotine on the output of dopamine in the dorsal and ventral striatum of freely-moving rats. Naunyn Schmiedebergs Arch Pharmacol 362:444-447

Shoaib M, Stolerman IP, Kumar RC (1994) Nicotine-induced place preferences following prior nicotine exposure in rats. Psychopharmacology 113:445-452

Shoaib M, Thorndike E, Schindler CW, Goldberg SR (1997) Discriminative stimulus effects of nicotine and chronic tolerance. Pharmacol Biochem Behav 56:167-173

ShoaibM, Sidhpura N, Shafait S (2003) Investigating the actions of bupropion on dependence-related effects of nicotine in rats. Psychopharmacology 165:405-412

Stolerman IP (1989) Discriminative stimulus effects of nicotine in rats trained under different schedules of reinforcement. Psychopharmacology 97:131-138

Stolerman IP, Fink R, Jarvik ME (1973) Acute and chronic tolerance to nicotine measured by activity in rats. Psychopharmacologia 30:329-342

Stolerman IP, Garcha HS, Pratt JA, Kumar R (1984) Role of training dose in discrimination of nicotine and related compounds by rats. Psychopharmacology 84:413-419

Tinsley MR, Timberlake W, Sitomer M, Widman DR (2002) Conditioned inhibitory effects of discriminated Pavlovian training with food in rats depend on interactions of search modes, related repertoires, and response measures. Anim Learn Behav 30:217-227

Walter S, Kuschinsky K (1989) Conditioning of nicotine effects on motility and behavior in rats. Naunyn Schmiedebergs Arch Pharmacol 339:208-213

Warburton DM, Wesnes K, Shergold K, James M (1986) Facilitation of learning and state dependency with nicotine. Psychopharmacology $89: 55-59$

Wasserman EA, Miller RR (1997) What's elementary about associative learning? Ann Rev Psychol 48:573-607

Wasserman EA, Franklin SR, HearstE(1974) Pavlovian appetitive contingencies and approach versus withdrawal to conditioned stimuli in pigeons. J Comp Physiol Psychol 86:616-627

Wiley JL, LaVecchia KL, Martin BR, Damaj MI (2002) Nicotine-like discriminative stimulus effects of bupropion in rats. Exp Clin Psychopharmacol 10:129-135

Yin R, French ED (2000) A comparison of the effects of nicotine on dopamine and non-dopamine neurons in the rat ventral tegmental area: an in vitro electrophysiological study. Brain Res Bull 51:507-514

Young R, Glennon RA (2002) Nicotine and bupropion share a similar discriminative stimulus effect. Eur J Pharmacol 443:113-118 